remarkable African affinity' in the Lepidoptera of Aus. tralia, in reference to the case of the larva of Doratophora vulnerans Lewin. The instances which he cites as analogous, however, are very different in character, for he quotes the mention by Livingstone ' of a caterpillar called Rigura, producing fearful agony if a sore is touched with its entrails'; and the statement made by Baynes and other travellers, that a caterpillar is used by the Bushmen to poison their arrows. It is evident that, if a caterpillar be used at all for poisoning arrows (concerning which report my inquiries have hitherto been attended by no satisfactory result) it must be the intestines or juices of the animal which are so employed. But the case of Doratifera vulnerans is the common one of (what appears to be mechanical) irritation, by means of clusters of spines, a defence possessed by many caterpillars, not only in Australia and South Africa, but throughout the globe, and of which the larva of the European Cuthocampa processionca presents a familiar example. Duncan (Nat. Libr. Ent. vol. vii. Exotic Moths, pp. I \&I-2. pl. xxii. f. 5) represents the larva of $D$. vulnerrans as possessing four fascicles of rufous spines, exsertile at will on both the anterior and posterior portions of the body, and quotes Lewin to the effect that the wound inflicted by the fascicles is very painful. According to. Mr. Murray's account it would appear that the African larvx, from the handling of which Dr. Welwitsch expcrienced such suffering, were near allies (if not actually species of Doratifera); and the con. clusion is obvious that it was by fascicles of spines that the pain was occasioned-not an uncommon case in the warmer parts of the world, and one by no means indicative of any special relation between the Lepidopterous faunas of South Africa and Australia."

$\mathrm{Mr}$. Trimen is obviously right as to the absence of analogy between the venomous properties of the cater. pillars spoken of by Livingstone and Baynes, and those met with by Dr. Welwitsch, and it was a slip on my part to collocate them together; but I am not satisfied that he is equally right in referring the pain caused by the species of Doralophora to mechanical irritation. He gives no facts in support of his assumption to that effect, and the facts communicated to me by Dr. Welwitsch regarding the insect from which he suffered scem to me wholly inconsistent with that supposition. It may be supposed from his and my silence that we acquiesed in $\mathrm{Mr}$. Trimen's views. But it is not so. IVhen Mr. Trimen's paper appeared Dr. Welwitsch spoke to me upon the point, and I urged him to communicate to the scientific world fuller details of the incident than I had given, and I understood that he intended to do so in any account of the insects collected by him. I therefore did not feel warranted in speaking, which I now regrct, for as with much else that he had on hand to do, his life has been too short for him to do it himself. Now that he has passed away from us I should not like an erroneous impression to exist as to the facts; and although I have little to add to what I formerly stated as communicated by him to me, I should wish to repeat it more precisely, and to say that Dr. Welwitsch himself was firmly convinced that it was not a case of mechanical irritation but of a special virus of unusual potency.

In the first place, then, Dr. Welwitsch had heard of this noxious caterpillar before he met with it-the natives knew it well and dreaded it. In the next place when he did meet with it his native attendant warned him of itand they took every precaution against touching it ; they plucked leaves on which the caterpillars were feeding and giided them from the leaf into the wide-mouthed bottle or vessel he had to carry such specimens home in. They also took specimens of the plant on which they were feeding. I suggested to him that the sting might have been in the plant, but this he was positive was not the case. The virulence of the venom was such that by the time they reached home in an hour or so after, every tender part of their body which they had touched with their tingers had become swollen and inflamed; their eyes were closed up, their lips and cheeks swollen as if they had been assisting (as principals) at a prize fight, and the consequent fever was so great that they were laid up, unable to move for two or three days; and when they did get up he found that their attendants had bundled out of the house both the caterpillars and the plants on which they fed. Now it seems to me that mechanical irritation is a wholly inadequate cause for such extreme inflammatory action. Mechanical irritation may go a certain length, but there are bounds beyond which we must look for some other explanation.

But first we want more facts and more examples. I exhibit two caterpillars, apparently different species, which I have received from Old Calabar, given to me with a notandum as reckoned injurious if not venomous, but my information as to them is too vague to allow me to cite them as positive examples of venomous caterpillars. And I also show one from Brazil which I have received from my friend, Mr. Fry, which he informs me bears a very bad character in Brazil. Both of these, indeed, all to which this property has been ascribed, are hairy caterpillars; but then it is onlyinairy caterpillars that seem to have the necessary apparatus for stinging-all stinging plants, so far as I know, are hairy. If the caterpillars have a special venom, then, as in the nettle, there should be a gland at the base of each hair, which should be hollow, and the spines in most, if not all, our caterpillars are hollow. I know of no physiological reason against their being so made. In the skin of the newt there are pores which exude an acrid irritating fluid. If a hollow hair were placed over the pore with proper muscles, we should then have a parallel to the supposed case.

But, as I saf before, we want information as to the existence and amount of this venomous property, and the chief object of this paper to-night is, after eliciting the views of the meeting, to suggest to those who may have the opportunity, the desirableness of making observations on the point.

A. Murray

\section{ON SPACE OF FOUR DIMENSIONS}

$W^{E}$ may define space as that which indicates and measures the extension of the Universe. We may determine the form and position of any material object by assuming three infinite planes, fixed in infinite space, and at right angles to each other. Space then is the room occupied by matter, or included between distant masses of matter; and, as such, we know of it only as possessing three dimensions:-length, breadth, thick-
ness.

Descales (Principia pars. 2, "Quid sit spatium, sizle locus internu(") remarks, "For, in truth, the same extension in length, breadth, and depth, which constitutes space, constituted body; and the difference between them consists only in this: that in body we consider extension as particular, and conceive it to change with the body; whereas in space we attribute to extension a generic unity (genericam unitatem), thus after taking from a certain space the body which occupied it, we do not suppose that we have at the same time removed the extension of the space, because it appears to us that the same extension remains there so long as it is of the same magnitude and figure, and preserves the same situation in respect to certain bodies around it, by means of which we determine the space."

Gauss used to say that one of the happinesses of his future life would be the amplification of his conceptions of space; the realisation of that which he had once known as space of three dimensions, as space of four dimensions. For just as we can conceive of beings "like infinitely attenuated book-worms in an infinitely thin 
sheet of paper," which can realise space of only two dimensions, so also we may conceive of beings capable of realising space of four dimensions. Prof. Sylvester, Dr. Salmon, Prof. Clifford, and others, have indicated in some of their profoundest mathematical demonstrations that they possess "an inner assurance of the reality of transcendental space." We desire now to bring forward, with great apology to the mathematicians for our temerity, some ideas, which we believe may enable even the least mathematical amongst us, to realise,-faintly, indeed, and very dimly-the possibility of cxistence of space, other than that which we now occupy. This we propose to do, (a) by attempting to realise a condition of life in space of two dimensions, and $(\beta)$ by adding the element of diverse motions, to our already known space.

Our knowledge of the Universe involves the conception of space, time, and number. These are intuitive notions : we cannot strictly define them; in the abstract our notion of them is merely relative; apart from material existence we cannot realise them. Extension is an essential property of matter, and our conception of space is linked with our conception of extension. Robert Hooke, in a series of lectures De Potentia Restitutiva, written nearly two hundred years ago, and too little known, defines a sensible body as "a determinate space, or extension, defended from being penetrated by another, by a power from within." Now this power may be most readily conceived to be a vibratory motion of the particles across a position of rest. Let us imagine an infinitely thin plane vibrating between two fixed points with such velocity that no other matter can penetrate into the space limiting the vibration, then a solid bounded in one direction by the two fixed points would be the result. For example, let an infinitely thin sheet of iron a metre square vibrate with extreme velocity in a span of one metre, and a cubic metre of iron would be the result. The rapid vibration of the plate would defend the range of vibration from being penetrated, and impenetrable material substance would result. An infinitely thin line vibrating between two fixed points would furnish a plane. An infinitely thin plane vibrating between two fixed points would furnish a solid. 'Thus by the addition of motion we can convert a determinate space, approximately of one dimension, into space of two dimensions; and by the addition of motion we can convert space of two dimensions into space of three dimensions. Can we conceive of any motion which given to space of three dimensions shall generate space of four dimensions? We do not know of such motion, but we can surely conceive the possibility of its existence. Space of four dimensions is transcendental space: it is beyond the limit of our experience, but not beyond the limit of our imagination.

Let us now endeavour to realise the condition of a being living in space of two dimensions. If man possessed the eycs and the power of flight of an eagle, superadded to his ordinary intellectual qualities, he would, no doubt, have very enlarged views of space. As it is, man is distinguished from the brute animals by his erect bearing, and the range of space which his vision enables him to scan. Our eyes are easily movable in various directions, so also is our head; by a slight movement of the head and eyes, we may take in either space bounded by the horizon, or by a surface a foot square. If we throw our head back we cnlarge our view of space; if we bend our head forward we narrow our view of space. Now, imagine that a man thus endowed, and with our own notions of space of three dimensions, begins to stoop forward and to grow so: his ejes survey less space; he stoops more forward; his body forms angles of $80^{\circ}, 70^{\circ}, 60^{\circ}, 50^{\circ}$ in succession, with a horizontal plane. Then he is obliged to go on all-fours, his limbs shorten and are gradually absorbed into the mass of his body; he crawls, he creeps; at length his limbs disappear altogether, and he trails himself along and glides like a serpent, moving in a hori- zontal plane. During these successive shrinkings in the direction of his thickness his head has become fixed, his eyes motionless, in the plane in which he moves, and his vision has hence become more and more limited. Now his body begins to diminish in thickness; he becomes thinner, and thinner, and thinner, and when he has become very thin indeed, let his thickness be expressed as the numerator of a fraction, while the denominator is an infinitely great number-say, if you will, as many figures as, written on paper, would reach ten billion miles, with ten figures to an inch. Now he is a mere plane, an infinitely thin surface; he occupies space approximately of two dimensions; his eyes are on a line. Try to imagine what the ideas of space of such a being would be; compared with our own ideas of space, compared with his own ideas before and during his process of flattening. $\mathrm{Hc}$ would now contemplate only a plane surface; he would see length and breadth without thickness. Compare also his ideas of space at each and every position between verticality and horizontality as his ken gets less and less, and at last the whole world is shut out from him.

Again, to come nearer home, and back again to the world of real existences, let us compare our own ideas of space after concentrating our vision for awhile on a book a foot square, with our ideas of space acquired while we ascend a lofty mountain, or lie upon our back on the deck of a vessel in mid-ocean. Compare the views of space possessed by a prisoner immured for forty years in a dungeon eight feet square, of La Sachette in the Trou aut $x$ Rats, of a being bed-ridden for half a century, with those of a hunter in the prairies of the West, a sailor of the Atlantic, even of a dweller in a flat tame country. The conceptions of space possessed by these different people will vary enormously. Contract the limits of space of possible contemplation; remove the possibility of contemplating space of great dimensions, and the faculty of such contemplation will itself die out; and thus, by a gradual process of diminution, we may arrive at our ideal being, living in space of two dimensions. Finally, let us imagine the bcing of two dimensions-length and breadth-to become narrower and narrower, and when he has become extremely narrow let us divide his breadth by an infinitcly large number, and he becomes approximately of one dimension; he has now only length; he lives in a line; his one motionless cye is a point.

So much for space of less dimensions than our own. Let us now try to conceive an extension of our ordinary space; and let us attempt this by the superaddition of motion to known space. And let us clearly realise the fact that one and the same thing may easily possess various motions at the same time. For instance, when I walk across the room, talking the while; my vocal chords possess fivc distinct motions: (a) their own proper motion of vibration; plus $(\beta)$ the motion of translation caused by walking forward; plus $(\gamma)$ the motion of rotation of the earth about its axis; $p l u s(\delta)$ the motion of revolution of the earth about the sun; plus (c) the motion of translation of the whole solar system through space. Let us suppose now that our bodies, instead of being at apparent rest, were to vibrate in arcs, with an amplitude of 10,000 miles, and with an infinite velocity; and let the plane of the direction of vibration itself vibrate between limits 10,00 miles apart; and let the whole vibrating system move with infinite velocity in a circle $1,000,000$ miles diameter; and let the circle rotate upon its diameter; and let the sphere of revolution thus formed revolve in an infinitely great ellipse; and let the ellipse rotate upon one of its axes; andbut hold ! we have surely arrived at a somewhat enlarged view of our own relations to space. Conceptions of this nature sufficiently pursued may, perchance, lead us to the very threshold of transcendental space; and, once on the threshold, we may look wonderingly beyond.

G. F. RODWELI. 